\title{
Mold-filling and Solidification Simulation of Grey Iron in Lost-Foam Casting
}

\author{
Mingguo $\mathrm{XIE}^{1, \mathrm{a}} \quad$ Changan $\mathrm{ZHU}^{1^{*}, \mathrm{~b}} \quad$ Jianxin $\mathrm{ZHOU}^{2, \mathrm{c}}$
}

1 School of engineering science, University of science and technology of China, Hefei 230026, China

\author{
2 State Key Laboratory of Materials Processing and Die \& Mould Technology, \\ Huazhong University of Science and Technology, Wuhan 430074, China \\ a.xiemingguo@sina.com, ${ }^{b . *}$ Corresponding author: changan@ustc.edu.cn, \\ c.zhoujianxin@hust.edu.cn
}

KeyWords: Grey cast iron, Lost foam casting, Simulation

Abstract: According to characteristic of Lost Foam Casting (LFC) processes and considering the metal flow pattern decomposition gas pressure impediment, interface elapse model is established base on gap pressure as boundary of front of melt flow. Corresponding numerical solution method is applied to simulate filling and solidification process of LFC. To verify the validity of the model, basic test model is introduced and compared the simulation results between LFC and general gravity sand casting. Finally, practical casting design of grey iron in LFC is given. The application shows that the proposed models could effectively predict the possible defect, and provide useful guidance for designer to optimize casting process solutions to directly improve the actual production.

\section{Introduction}

LFC is a technology near and precise shaped casting process which known as highly promising ${ }^{[1]}$. Different from the general cavity of sand casting, LFC is characterized in the role of negative pressure, foam models form in sealed tight sandbox dry sand. During liquid metal filling, the foam gradually form pyrolysis, gasification and liquefaction or discharged under the action of heat liquid metal and through the vacuum system. After the liquid metal replace original foam mold, the cavity is formed to be the casting. Classic lost foam casting processes is shown in Figure 1.

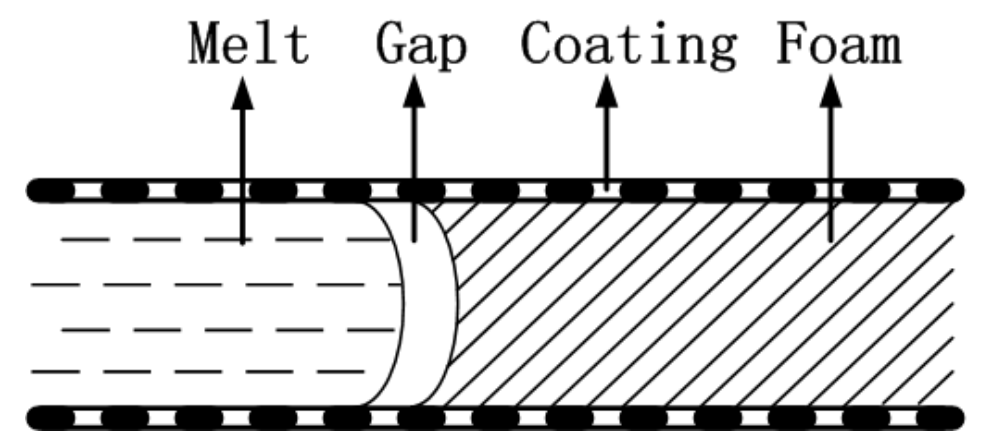

Figure 1 Classic lost foam casting processes

In recent years, researchers carried out extensive simulation and experimental research on the liquid metal filling process flow and heat transfer of LFC. Wang ${ }^{[2-3]}$, etc. analyzed for liquid metal 
flow and heat transfer in arbitrary three-dimensional geometry LFC aluminum alloy castings filling process, the results of actual measurements were compared; Chen ${ }^{[4]}$, etc. integrated on the computing model of the original ordinary sand casting flow field and suppose the passage of liquid metal free surface velocity is related to flow rate of liquid metal within the gate, thus established a model and verified the results with simple experiments. Gurdogan ${ }^{[5]}$, etc. used the combination solving the corresponding mathematical model and experiments in linear regression analysis, obtained the flow field simulation results; Ohnaka Itsuo ${ }^{[6]}$ given the calculation method and show some advanced simulation results and discussion for mold-filling in LFC ; Li Fengjun ${ }^{[7]}$ etc. got cutting-edge metal flow rate empirical formula according to the experimentally measure flow front velocity and by linear regression, and then simulate the passage of liquid metal flow front based on artificial neural network, finally simulate the entire flow domain; S.M.H.Miragheri ${ }^{[8]}$ etc. considered the nature of the flow and temperature field, defined a new SOLA-VOF algorithm combined with the air gap and fluid pressure, applied iterative calculate full mesh and partial mesh at the same time, thereby obtained a whole flow field results.

Moreover, the Bernoulli equation method ${ }^{[9]}$, limiting interface frontier speed method ${ }^{[5]}$, and backpressure amendment method ${ }^{[10]}$ and other methods ${ }^{[11]}$ to approximately simulate the status of LFC filling process were emerged among these research results. In this paper, we put forward a kind of mathematical models which in line with the disappearance of molded alloy filling characteristics based on the foregoing summary and research the results of the researchers, and applied to the numerical simulation program.

\section{Mathematical Models of LFC}

During the melt filling in LFC, complex physical and chemical phenomena is processing including heat transfer, filling flow, chemical reactions and cooling and solidification, etc. These phenomena are coupled together and influenced each other, so that the liquid metal filling process is more complex, and ultimately affect the casting quality. In the LFC process, the fluid phenomenon is governed by mass, momentum and energy conservation equations. The mathematical models could be described as follows ${ }^{[8]}$ :

1 ) The momentum transport equation

$$
\frac{D v}{D t}=-\frac{\nabla(\theta P)}{\rho}+\theta g+v \nabla^{2}(\theta v)
$$

2 ) The continuity equation for the liquid region is

$$
\frac{\rho_{L}-\rho_{S}}{\rho}\left[\frac{\partial f_{L}}{\partial t}+(\theta v) \cdot \nabla f_{L}\right]+\nabla \cdot(\theta v)=0
$$

Where $f_{S}$ and $f_{L}$ are solid and liquid fractions, respectively.

3 ) The heat transfer equation

$$
\rho C_{P} \frac{\partial T}{\partial t}=-\rho C_{P} v \cdot \nabla T+\nabla \cdot q
$$

4 ) The fraction volume of control element occupied by the fluid 


$$
\frac{\partial F}{\partial t}+\nabla \cdot v F=0
$$

5 ) The decomposition function of foam for high melting point metals is descried by

$$
P_{S}=n m \rho_{F B}\left[1+\stackrel{-V}{V}_{R}^{r}\right] \Delta V_{M} \text {, where } \Delta \mathrm{V}_{\mathrm{M}}=\Sigma\left(\mathrm{F}_{\mathrm{i}, \mathrm{j}, \mathrm{k}}^{\mathrm{n}+1}-\mathrm{F}_{\mathrm{i}, \mathrm{j}, \mathrm{k}}^{\mathrm{n}}\right) \Delta \mathrm{x} \Delta \mathrm{y} \Delta \mathrm{Z}
$$

\section{Numerical exemplification and application}

\section{(1) Basic numerical example and analysis}

In order to verify the reliability of the developed mathematical models, we study the basic model as show in Figure 2, and parameters of calculation the are shown in Table 1.

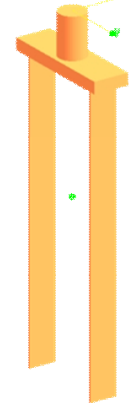

Figure 2 Calculation Model
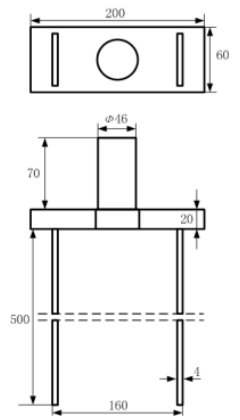

\begin{tabular}{|c|c|}
\hline \multicolumn{2}{|c|}{ Table 1 Calculation Parameters } \\
\hline Pattern material & Polystyrene (EPS) \\
\hline Pattern density $\left(\mathrm{kg} / \mathrm{m}^{3}\right)$ & 0.00002 \\
\hline $\begin{array}{c}\text { Latent heat of vaporization } \\
(\mathrm{J} / \mathrm{kg})\end{array}$ & 0.982 \\
\hline Coating permeability $\left(\mathrm{m}^{2}\right)$ & $0.5 \mathrm{E}-11$ \\
\hline Coating thickness $(\mathrm{m})$ & 0.02 \\
\hline Pouring temperature $\left({ }^{\circ} \mathrm{C}\right)$ & 1400 \\
\hline Alloy & HT 200 \\
\hline
\end{tabular}

As shown in Figure 3, in the case of top pouring, due to back gas pressure by gasification and decomposition of molten foam, melt flows into inlet from top to bottom and the shape of flow become radially forward layer by layer. After filling the runner over, in the long thin place, the melt advance step by step manner fill down. By the simulation results and analysis, the results are consistent with theoretical LFC filling properties.

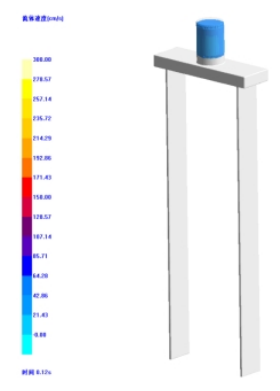

(a) $0.12 \mathrm{~s}$

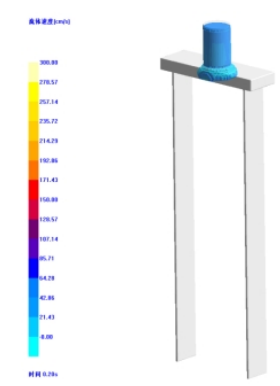

(b) $0.20 \mathrm{~s}$

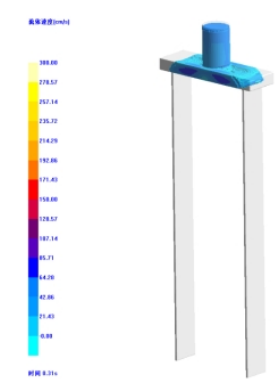

(c) $0.31 \mathrm{~s}$

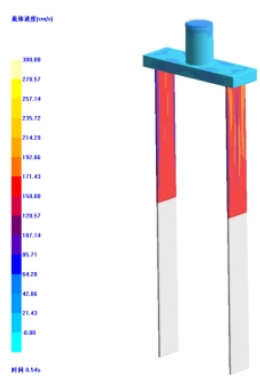

(d) $0.54 \mathrm{~s}$

Figure 3 Fluid velocity at different filling time

In order to analyze mold filling process characteristics in LFC, we use the same model in general gravity casting, and the simulation results of two different casting methods were analyzed. 
As shown in Figure 4, when the melt flow into the inlet, flow shape of lost foam casting radial shape, while in gravity casting, there are rain state; When melt flow into the runner, flow shape will remain in the liquid metal layer to promote, while in gravity casting filling the distal and larger turbulence; when melt flow fills up, in LFC flow shape still layered metallic liquid propulsion and fill down, and in gravity casting flow will be more disordered state into the area, and the state will be presented and rain. From the above analysis, the model proposed could be better presenting filling characteristics in the LFC.
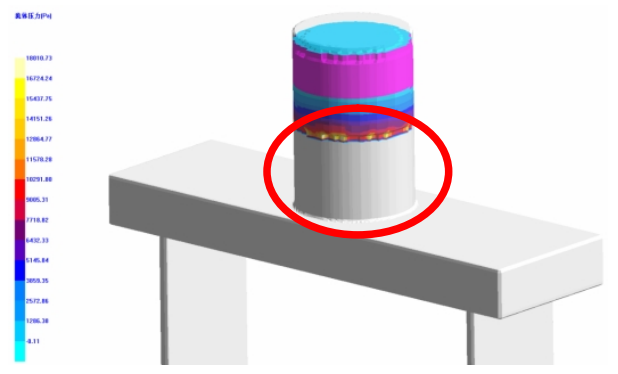

$0.08 \mathrm{~s}$
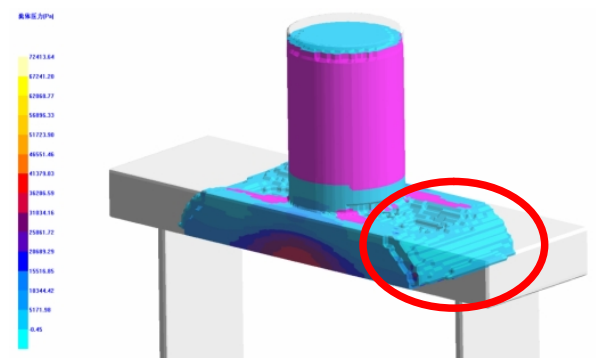

$0.28 \mathrm{~s}$

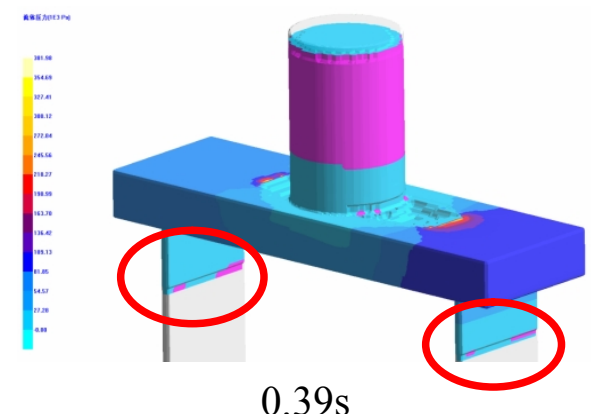

( a ) LFC
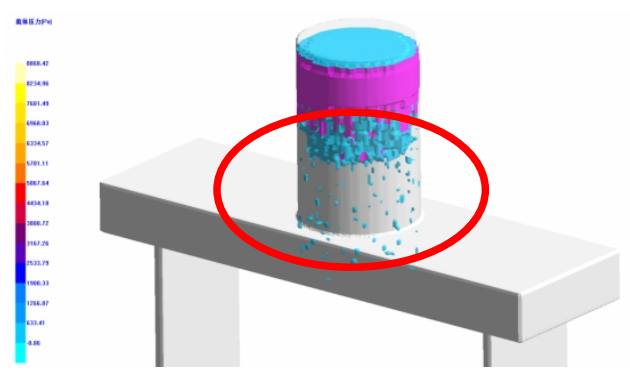

$0.07 \mathrm{~s}$
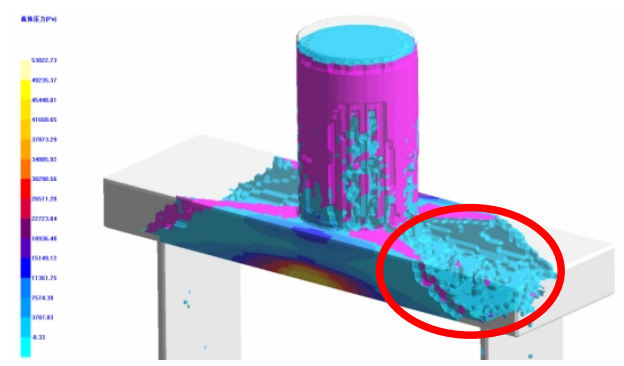

$0.20 \mathrm{~s}$

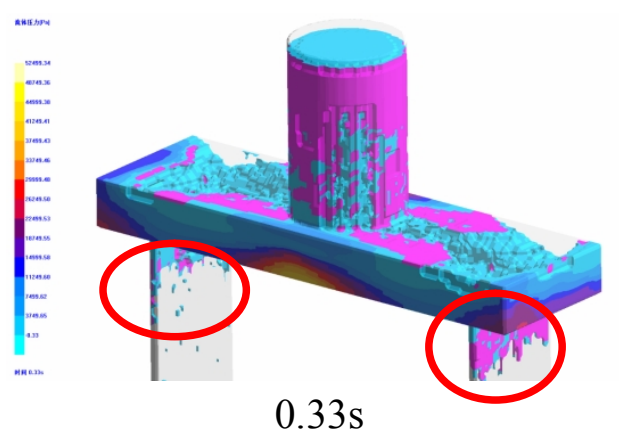

( b ) Gravity Casting

Figure 4 Fluid pressure at diffierent filling in diffierent casting process

\section{(2) Practical example and analysis}

In practical applications, filling and solidification process could be simulated to obtain flow field and temperature field information and analyze possible defect raised by process design. In this paper, the actual castings production design is applied: casting alloy is grey iron HT 250, the pouring temperature is $1400{ }^{\circ} \mathrm{C}$, dry sand molding and set the negative pressure -0.04MP. Combined with the traditional process design principles, two casting process design is proposed and casting process model shown in Figure 5. After geometrical model meshing, and setting physical parameters, the two casting design of casting in LFC is simulated. 

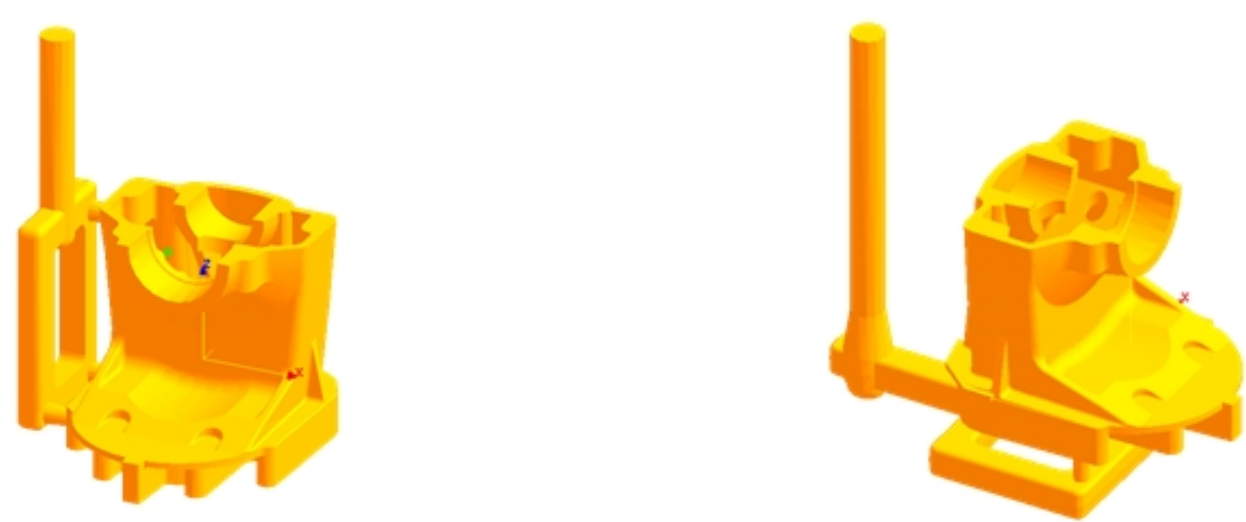

Figure 5 Two casting design of casting in LFC(Left: scheme 1; Right scheme 2)

\section{Simulation and analysis in scheme 1}

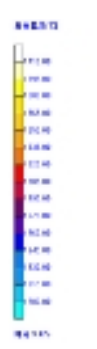

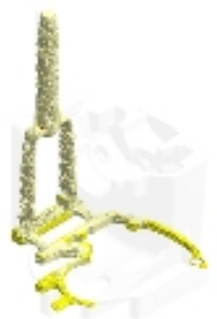

(a) $10 \%$

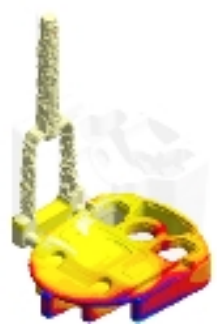

(b) $40 \%$

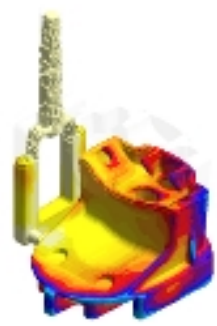

(c) $70 \%$

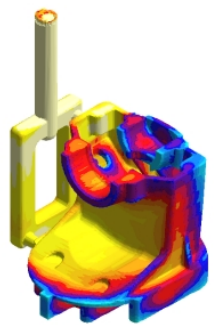

(d) $100 \%$

Figure 6 Fluid temperature at different filling time in scheme 1

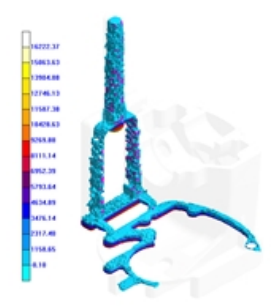

(a) $10 \%$

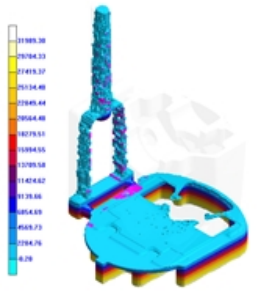

(b) $40 \%$

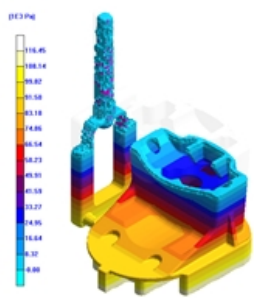

(c) $70 \%$

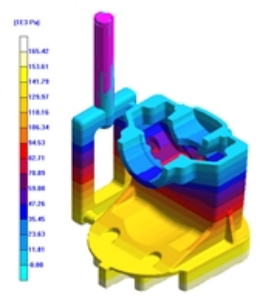

(d) $100 \%$

Figure 7 Fluid pressure at different filling time in scheme 1

Flow Field Analysis: From simulation analysis in Figure 6 and 7, the melt flows from the bottom to top. B gas pressure from the foam mold vaporized, significant rain and splash phenomenon does not appear. At the same time, the fluid velocity and temperature at flow front is reduced rapidly. At the end of filling, at the second layer on top of the casting runner new melt significantly give temperature supplement to ensure the uniformity of the initial solidification temperature of the casting. 

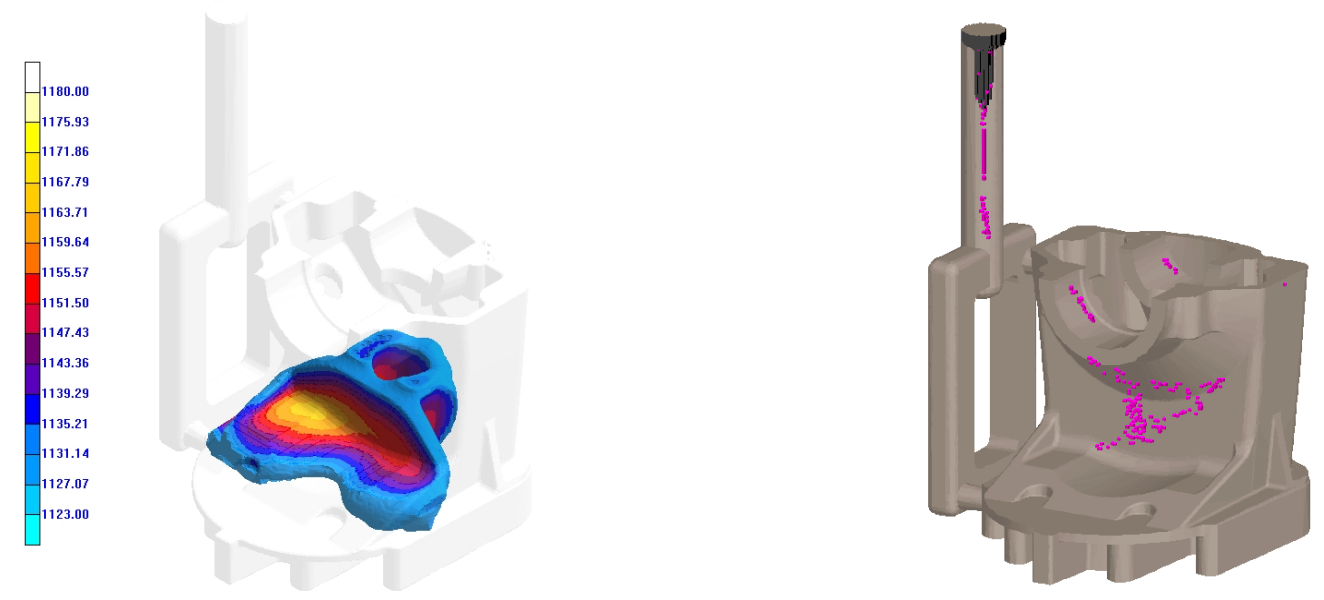

Figure 8 Isolated liquid at one solidification time Figure 9 Shrinkage defect

Temperature Field Analysis: In the solidification process, in the casting thick uncured isolated liquid most likely formed, easy to form shrinkage defects if they are not feed. In solidification process of scheme 1, a larger portion isolated liquid region (Figure 8) in connection part, a liquid will continue to shrink, and role of ferroalloy graphite precipitation will produce expansion. Based on consideration of these two effects, scattered shrinkage final form in this region (Figure 9), shrinkage volume is $21.5 \mathrm{~cm}^{3}$. Process improvement needs according to quality of practical casting part.

\section{Simulation and analysis in scheme 2}

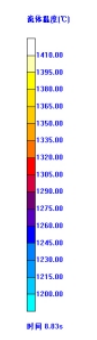

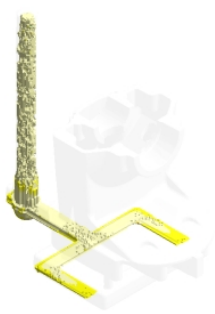

(a) $10 \%$

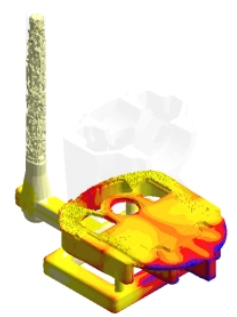

(b) $40 \%$

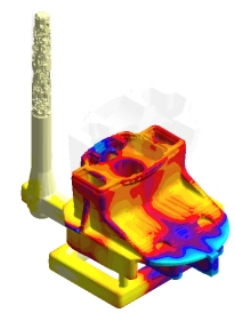

(c) $70 \%$

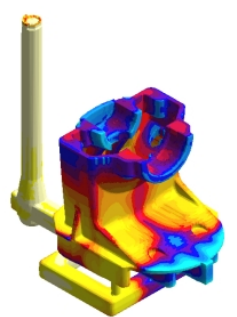

(d) $100 \%$

Figure 10 Fluid temperature at different filling time in scheme 2

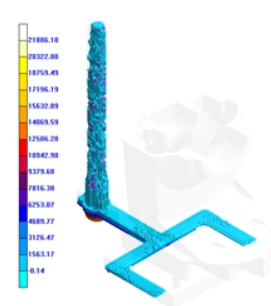

(a) $10 \%$

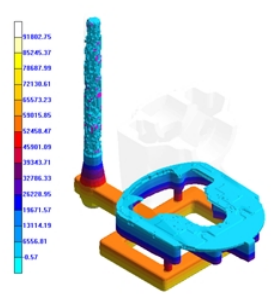

(b) $40 \%$

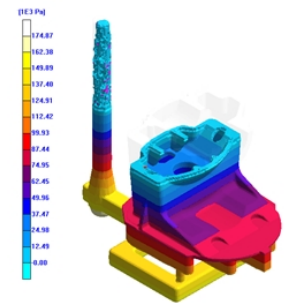

(c) $70 \%$

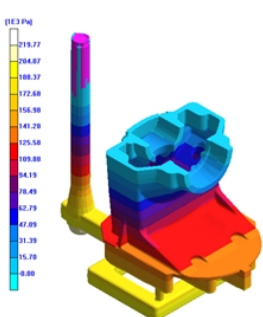

(d) $100 \%$

Figure 11 Fluid pressure at different filling time in scheme 2

Flow Field Analysis: From simulation analysis in Figure 10 and 11, the melt flows from the bottom to top. By gas pressure from the foam mold vaporized, significant rain and splash phenomenon does not appear as well. At the same time, the fluid velocity and temperature at flow front is reduced rapidly. 

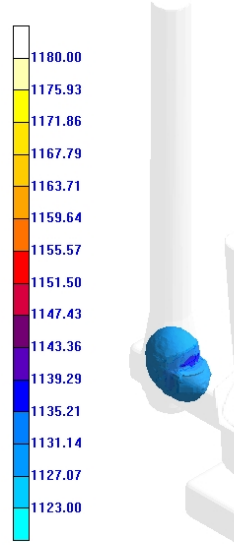

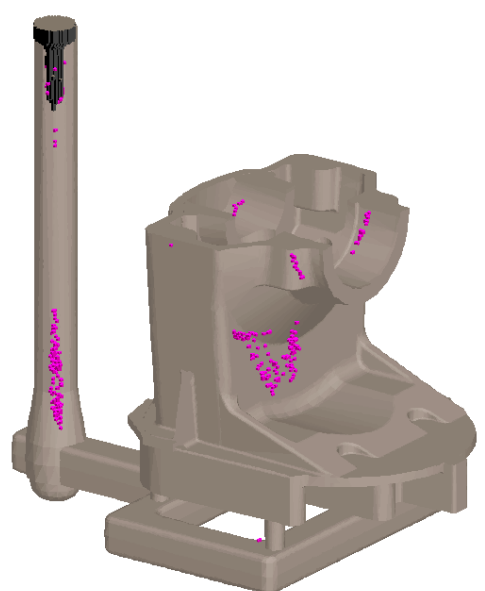

Figure 13 Shrinkage defect

Figure 12 Isolated liquid at one solidification time

Temperature Field Analysis: In the process of Scheme 2 solidification process, smaller isolated liquid region is formed (Figure 8) and also consider the metal solidification shrinkage and ferroalloy graphite precipitation expansion. Some dispersed shrinkage is found, shrinkage volume: $12.12 \mathrm{~cm}^{3}$. The volume of defect tends to be less than in scheme 1 .

\section{Conclusion}

In this paper, interface elapse model is established base on gap pressure as boundary of front of melt flow. By validation and comparison of the basic model, the proposed model can reflect the disappearance of flow shape by melt filling. Under negative pressure environment by vapor pressure, the flow velocity and temperature of melt significantly reduced at front of melt flow. Meanwhile, the actual casting process of two different designs is simulated to investigate filling and solidification process and defect prediction. Two designs could ensure the smooth flow of melt filling. Scheme 1 could ensure temperature balance of upper and lower part; Scheme 2 could be effectively reducing shrinkage defects. Thus, the simulation results could help design evaluating different process design, to do corresponding improvement measures, and ultimately to reduce the number of experiments and improve process design level.

\section{Reference}

[1] Fan Z T, Jiang W M. Development Trend and Status of Lost Foam Casting Technology [J] (in Chinese). Foundry, 2012(6): 583-591

[2] Wang C, Ramsay C W, Askeland D R. Effect of Processing parameters on mould filling for gray iron EPC castings statistical experimental techniques. AFS transaction, 1994, 102: 921-930

[3] Wang C M, Paul A J. Computational analysis of fluid flow and heat transfer during the EPC process. AFS Transaction, 1993, 101:897-904

[4] Chen Y F, Chen R C, Hwang W S. Mould-filling study in the EPC process-mathematical model and flow characteristics. AFS Transaction, 1997, 105: 459-464

[5] Gurdogan O, Huang H, Aakay H U, etc. Mould-filling analysis for ductile iron lost foam 
casting. AFS Transaction, 1996, 104: 451-459

[6] Ohnaka Itsuo, Sugiyama Akira, Konishi Kunihiko, et al. Computer simulation of lost foam process of cast iron [J]. Key Engineering Materials, 2011, 457: 299 304

[7] Li F J, Shen H F, Liu B C. Modeling of mold filling and solidification in lost foam casting [J](in Chinese). Journal Science and Technology, 2003, 19(5): 395 397

[8] Mirbagheri S. M. H., Serajzadeh S, Varahram N, et al. Modeling of foam degradation in lost foam casting process [J]. Materials \& Design, 2006, 27(2):115 124

[9] Liu Ying, Bakhtyarov Sayavur I, Overfelt Ruel A. Experimental study of EPS decomposition in lost foam casting process [J]. American Society of Mechanical Engineers, Fluids Engineering Division (Publication) FED, 2000, 255: 79 84

[10] Jer-Haur Kuo, Jui-Ching Chen etal. Mould Filling Analysis in Lost Foam Casting Process for Aluminum Alloys and It's Experimental Validation. Materials Transaction[J], 2003, 44: 2169-2174

[11]Barone M, Caulk D. Analysis of mold filling in lost foam casting of aluminum [J]. International Journal of Metalcasting, 2008, 2(3): 29-43 